\title{
Writing Sonic Fictions: Literature as a Portal into the Possibility of Art Research
}

\author{
Salomé Voegelin
}

\begin{abstract}
:
This text writes a short deliberation on the potential of literary writing and literary study to establish the possible worlds of fiction as an exploratory sphere within which we can tease, from the ambiguity of art, its contribution to research and knowledge without suppressing the sensorial and aesthetic dimension of its material. The literary is presented as a modest collaborator to the artistic investigation: aiding its articulation without erasing its processes and speechlessness. This approchement of work and text is critiqued and augmented through the radical reality of sound and the notion of sonic fictions that breach analytical language to speak its excess.
\end{abstract}

\section{Introduction}

One of the most powerful moments in Philippe Parreno's installation Anywhen, a multi-media, multi-thing and arguably multi-time and multi-space work shown in the Turbine Hall at Tate Modern between October 2016 and April 2017, is a video of ventriloquist Nina Conti with her dummy standing mute in a huge, floodlit but empty auditorium, listening to a recording of her own as well as her ventriloquised voice. Her eyes stare awkwardly into the bright light, the dummy looks prostrate, deflated, and at the same time, there is a sense of anticipation: some sort of reveal has to happen, an explanation is expected from the darkness behind the bright spots of light that frame them both as a mute spectacle.

Who is ventriloquising the ventriloquist?

This text provides a short reflection on how to articulate the knowledge of art without speaking for it. It engages in the emerging discourse and practice of art research in relation to the possibility of literature, repositioned through the notion of sonic fictions. Thus it measures literary writing and elements of literary study in relation to the current endeavour of establishing art research as a legitimate agent in the production of knowledge and evaluates its potential through the radical reality of sound. The focus on sound and a sonic literacy 
introduces a sensibility for the invisible, for what comes out of the dark and is without a source or a name, and includes doubt in visual, systematic definitions, in favour of calling things contingently what they might be for now.

In the process of making this association between literature, sound, and art, other things come in to play. Inevitably the focus on art and knowledge turns an essay on methodological ideas towards the principle of the project itself, and confronts the objective of articulating art's sense by contemplating disciplinary investments, histories, and ideologies.

In the background of the question about who, what discipline, 'throws' its voice onto the stage to make the artistic dummy speak, rests the pervasiveness of a taxonomical consciousness and lexical norms of thinking post-Kant, which at once enable but also demand quantification and consensus. But the query as to the articulation of art's knowledge is impelled also by the radical jouissance of another voice that sounds for example in Julia Kristeva's poetic language that does not stop for signification but performs the "endless mobility" of the text, imploding the stability of signification and putting words and meanings on trial,; and that resounds in Hélène Cixous's "indispensable ruptures and transformations" that unravel what it is possible to write and what it is possible to mean. ${ }^{2}$ Their mobile rupturing of the infrastructure of epistemological thinking leads to a debate on the (mis-)conception that words and letters provide meaning that is more stable and systematic than that of any other expression; and informs a discussion, directed via the fictions of a conceptual sound, on the potential of literary fictions to tease from the work its own thinking, while being aware that maybe art cannot write at all.

\section{The Speechlessness of Art}

If thinking is a project of intelligible words, then art is the unthinkable. Not because it might not use words but because the words it uses almost immediately cease to comply with semantic meaning and instead drag communication into the opacity of the material: its sounds, its breath, its graphic image, rather than what it meant to say.

According to Howard Cagyll, a Kantian philosophy of language still today, totally and almost imperceptibly so, pervades our conception of language as a

1 Julia Kristeva, Revolution in Poetic Language (1974), translated by Margaret Waller. New York, NY: Columbia University Press, 1984, p. 102.

2 Hélène Cixous, "The Laugh of the Medusa" (1975), translated by Keith Cohen and Paula Cohen, in: Elaine Marks/Isabelle de Courtivron, eds., New French Feminisms. Hemel Hempstead: Harvester Wheatsheaf, 1981, pp. 245-264: here p. $25^{-}$. 
lexical resource. It represents the cornerstone of Western thought, decisively influencing the organisation and possibility of our thinking, speaking, and writing in quantifiable epistemologies of meaning and reference. Although, according to Caygill, Kant's views on language were more open-ended and discursive than some would come to interpret and use them, or indeed criticise them for, what is relevant here is that its analogical definitions lend a hand to structures, networks, taxonomies, and lexicons and thus set the parameters of the possibility of knowledge, identity, and thought, and delineate as unthinkable and impossible that which falls outside of it. ${ }^{3}$

The pervasiveness of Kant's conception of language means that it is not only within the remit of philosophy but across the broader cultural consciousness, its sense of signification and truth, that a Kantian language frame influences the definition of the real and thus delimits the scope and articulation of knowledge. Kant's conception of language as an analytical device enables taxonomies of abstract knowledge and creates structures about what things are and how the world is. They grant legitimacy, enable consensus and communication, but at the same time they exclude, without acknowledging this exclusion, that which falls outside the remit of its organisational framework: the opaque, sensate materiality, the invisible and the inaudible, whose appearance has no letters to form a definition and whose shape cannot be recognised in words. Kant's language calls subjects and objects within an etymological and symbolic frame that grants their image a visible form, but hides what else they might be, and ignores what else there might be. It speaks for them but not with their voice, and leaves speechless that which cannot be known within its frame.

This speechlessness is the fate of Nina Conti and her ventriloquist dummy. Their voices were stolen by the interpretative act of audio-visual montage; they stand and stare as their words are played back at them from behind bright lights and without their say-so. The absurdity of playing, out of synch and disconnected, two voices that for their communication and intelligibility rely on the invisible synchronicity and connection of ventriloquy, is an allegory for the confusion and ethical dilemma of the voice about art research. It points to what Jessica Worden, in her text "Articulating Breath: Writing Charcot's Hysteric with Performance Writing" 4 calls "the site of failure," where "the thing is fixed,

3 Howard Caygill, A Kant Dictionary. Oxford: Blackwell, 1996, pp. 1-7.

4 Worden refers her interpretation of performance writing to Ric Allsopp who articulates it as an investigation of the performance of writing; and practises it in accordance with Caroline Bergvall as a spatial and active juxtapositions of source material "incorporating every aspect of the writing making process as part of the work." (Jessica Worden, "Articulating Breath: Writing Charcot's Hysteric with Performance Writing," in: New Voices Forum, Arts \& Humanities in Higher Education 3:3 (2014), pp. 318-325: here p. 319.) 
in a word ... I think you're trying to worm it out of me," where, in other words, interpretation is revealed as manipulation, as "a speaking for." ${ }^{5}$ Worden discusses Jean-Martin Charcot's writing on behalf of the hysteric who is defined by her inarticulacy. While I want to avoid the equation of the artist as hysteric, Worden's observations, which motivate and inform her approach, foreground implicit ethical concerns of an ill-conceived custodianship of another person or another discipline. The medical voice deforms the experience of the patient through the expectation of its vocabulary and disciplinary objective. Documenting her illness, Charcot obliterates the hysteric's voice, excluding her body from the authority of the text. Performing these texts, as Worden does, she brings the body back into play and the authorial text into conversation with other texts and other visual material, diluting its singularity. However, despite the performative rendition, and the plurality of voices, the inarticulate voice of the hysteric remains absent, its sense translated, bridged rather than expressed in the montage of materials and documents. The plurality of sources and media used in performance writing provides multiple perspectives, and the performative reading grants the text temporality and contingent references, but the disciplinary context, its expectation, and analytical framework, nevertheless are in conflict with the possibility of inarticulation, which remains unheard.

The academic custodianship of artistic research leads to what Henk Borgdorff calls "border-violations" that according to him "spark a good deal of tension" (between art and academia) and that I understand to resemble the violations of the patient being made to speak the language of the medical discipline, rather than that of its own body. 6 "She does not make a sound. No air, no breath, no noise. How do you write an inarticulate state like this?"7 For Worden writing is crucial in giving the inarticulate a voice, but she also acknowledges that failure is inevitable "because of the resistance on the part of the subject." 8 The artistic subject, too, resists language. Its body is in process, on trial, it does not signify but means through modes of thinking and doing. For art to contribute its knowledge equitably to the table of research, the ambiguous, unreliable, and incomplete of this process must be made accessible, rather than be explained or translated in a metalanguage with its own interests in the stakes of knowledge.

5 Worden (2014), Articulating Breath, p. 324.

6 Henk Borgdorff, "The Production of Knowledge in Artistic Research," in: Michael Biggs/ Henrik Karlsson, eds., The Routledge Companion to Research in the Arts. London: Routledge, 2012, pp. 44-63: here p. 44.

7 Worden (2014), Articulating Breath, p. 320.

8 Worden (2014), Articulating Breath, p. 324. 
These reflections inform my view that academic scholarship should not colonialise and take over the body of art in order to speak for it in its disciplinary erudition, but to let the work, inarticulate as it might seem, establish its own voice and sense of things. So it might cease to be articulated as a failure of articulation, as what cannot be known, but comes to be understood and valued as the future of knowledge that informs and creates a language and an articulation that stretches beyond the lexicon, into the unthinkable and the unimaginable, which we might have to make use of to solve those problems that we do not have answers for and those that we do not yet know.

\section{Literature as a Modest Collaborator}

Towards the end of his essay "The Production of Knowledge in Artistic Research," Borgdorff engages in questions of "appropriateness" of documentation for art research, to do it justice and to report accurately on its findings. While he includes the possibility of non-verbal forms of outcomes, he still values language as an important tool in the evaluation process. But rather than staging it as an interpretative voice he calls it a complimentary medium "to help get across to others what is at issue in the research-provided one keeps in mind that there will always be a gap between what is displayed and what is put into words." ${ }^{9}$ He does not seek to bridge this gap, as Worden does, but wants it acknowledged as the condition of the articulation of artistic knowledge exactly. Thus language does not make art speak but compliments its expression and as Borgdorff suggests "a certain modesty is due here in view of the performative power of material outcomes." 10

As such a 'modest collaborator' literature and the poetic can circumvent the abstraction of interpretative mechanisms which ventriloquise. They can do so by putting language on trial: by writing in signifiers that keep on signifying but never really "mean."11 Or they can take from the oral tradition the power of the performative to structure a different imaginary: unperforming conventional identities and the values of a ruling voice ${ }^{12}$ and "sweeping away syntax,

$9 \quad$ Borgdorff (2012), Production of Knowledge, p. 58.

10 Ibid.

11 Kristeva (1984), Revolution in Poetic Language, p. 104 outlines a signifying practice of the "text," where "the commotion the practice creates spares nothing: it destroys all constancy to produce another then destroys that one as well."

12 Cf. Hélène Cixous/Catherine Clément, The Newly Born Woman (1975), translated by Betsy Wing. London: I.B. Tauris Publishers, 1996, p. 6. 
breaking that famous thread" by articulating the excess of language and what remains unsaid. ${ }^{13}$

This linguistic excess-this writing without grammar and the unperformance of the language base-critiques the capacity and prejudice of analytic language, the norms it represents and fosters, and generates instead expressions that might be able to account for the invisible and the inaudible and that might write a language in which art can speak itself as knowledge. The excess of writing without syntax, understood as the grammatical and disciplinary structure of words and their aim, is embraced also by Erin Manning and Brian Massumi in their book Thought in Act (2014). In its introduction, Manning and Massumi identify philosophy's outside as a "generative environment" that offers itself to think collaboratively the act of doing the impossible. ${ }^{14}$ Whereby the impossible in this context is not really what does not or cannot exist, but what we do not yet know, giving the collaboration a generative and future capacity rather than an interpretative role. Their close focus on work, on movements and expressions of the body and speech rather than language, attaches a positive and curious energy to the excessive. Accordingly, language articulates not as a precarious bridge nor as an inevitable gap but as a deliberate breach "in the fragile difference between models of thought in the act," breaching the limits of language to speak its excess. ${ }^{15}$ To identify this excess Manning and Massumi recall the break with meaning in teenage speech: "It's like this. Just like, sad." This phrase does not pursue designation and definition but voices a more refracted sense on the border of speechlessness, uttering sensation. "It marks an affective overflow in speech." It is just like sad is: it "overfills, its designation," and opens towards the possibility of a sensorial sense articulating the impossible. ${ }^{16}$

This openness towards the possible and the impossible as the sensorial sense of speech finds a parallel in Ruth Ronen's exploration of the literary text through possible world theory. The modal realism of possible world theory allows literary study to separate the idea of a text as expressing truth in relation to an outside-story from the truth of the object or event within the text. "Truth no longer involves a fixed and absolute standard by which true and false worldversions are judged, and by which fictional worlds are rejected from the realm

\footnotetext{
13 Cixous (1981), Laugh of the Medusa, p. 256.

14 Erin Manning/Brian Massumi, Thought in the Act: Passages in the Ecology of Experience. Minneapolis, MN: University of Minnesota Press, 2014, p. vii.

15 Ibid.

16 Manning/Massumi (2014), Thought in the Act, p. 34.
} 
of the true." ${ }^{17}$ Instead, the concept of truth has been replaced with the notion of "warranted assertibility" within a fictional world, which obeys flexible criteria of validation. ${ }^{18}$ Thus a literary text is understood to create a sphere away from the normative ideologies and expectations of analytical language, open to perform different relationships and find a different system of truth generation in a textual universe built on the excess of language, the incomplete, and the unthinkable.

Ronen goes on to suggest that this reassessment of truth has an impact beyond the text: "it enables us to see the actual world not as a given but as a set of propositions indexed by a different operator." 19 In this interpretation, the literary offers a language not of explanation but of proposition: proposing and generating in excess of existing knowledge the sense of sensation and demonstrating the ideological investment of existing knowledge paths.

Consequently, if literary fictions as textual actual and textual possible worlds can, according to Ronen, de-instrumentalise the relationship between the real and the text, they can also be used to de-instrumentalise and de-systematise the relationship between research, art, and writing. Instead of limiting the scope of intelligibility in relation to actuality and an analytical language, literary possible worlds can open the space for affective knowledge of excess and overflow laying bare the investments and ideologies of the actual and generating an alternative environment that articulates the seemingly impossible. Possibilia can invite us into a textual universe where the references are not analytical, bound to the taxonomy of the known, but fictional, driven by the reality of a future knowledge that is as yet unthinkable.

In this way, literary language can access different truths and generate different knowledge environments. It can use the poetic register of fiction and the fictional register of poetry to create a critical voice, which as a modest collaborator in the effort of 'documenting' and articulating art as research might provide the portal to the possibilities of arts' own terms.

However, for Ronen, possible world theory is interesting and useful for the exploration of fictional texts only as long as they remain autonomous of its philosophical background in logic as well as of the ontology of the actual world. "Possible worlds are based on a logic of ramification determining the range of possibilities that emerge from an actual state of affairs; fictional worlds are based on a logic of parallelism that guarantees their autonomy

\footnotetext{
17 Ruth Ronen, Possible Worlds in Literary Theory. Cambridge: Cambridge University Press, 1994, p. 41.

18 Ibid.

19 Ronen (1994), Possible Worlds, p. 39.
} 
in relation to the actual world."20 For Ronen, the textual universe remains removed from actuality. Literary fictions are parallel fictions: they have no actual impact or consequence on the real world. Therefore, while literature opens thinking to the (im-)possible, it lacks the legitimacy to impact on our knowledge base.

The issue here lies in the differentiation between the mere possibility of fiction and the perceived actuality of the real. This difference represents a gap that cannot be bridged but needs to be breached: fiction needs to be explored not as a proposition but as an action, which generates the real from unthinkable movements and invisible thoughts. I suggest that such a 'real fiction' is found in the invisible mobility of sound and a participatory listening that does not hear a source but generates its possibility from the ephemeral of sound itself. Thus I turn to Kodwo Eshun's More Brilliant than the Sun: Adventures in Sonic Fiction, where the ear "lingers lovingly inside a single remix, explores the psychoacoustic fictional spaces of interludes and intros, goes to extremes to extrude the illogic other studies flee. It happily deletes familiar names ... and historical precedence."21 Eshun's writing is an explicit attempt, in content and form, to critique, subvert, and expand how music is written about. It ridicules and effaces the conventions of music journalism and proposes a language that comes from sound, from its rhythm, from a bodily cerebrality that hears a techno future rather than follows the trajectories of the past into the present. This allows him to abandon the taxonomies and categories of history and its language, and in its stead, he produces dense narrations from sounds and rhythms that bring unprecedented valuations, demand neologisms, and trigger a physical engagement. While Eshun's sonic fictions are science-fictions for a musical production and thus only have an indirect relation to art research, they compellingly use the invisible mobility of sound and its untetheredness from the objective and a chronological line of thought to propose alternative paths to knowledge that are useful to reimagine the knowledge of art.

The use of possible world theory in relation to sound, just as for literature, is untied from its philosophical background, using rather than obeying conventions of logic, negotiating and subverting at times even its methods through the sensibility of the mobile and the invisible. However, unlike literary fictions, sonic fictions are not necessarily separate from the actual world. They are so only when considered visually: when their material is negotiated as a 'shadow' of a visual source, dependent for their meaning on correspondence and a textual referent. When listened to unseen, however, they sound in the actual world its possibilities. As an invisible thing sound does not propose but

\footnotetext{
$20 \quad$ Ronen (1994), Possible Worlds, p. 8.

21 Kodwo Eshun, More Brilliant than the Sun: Adventures in Sonic Fiction. London: Quartet Books, 1998, p. 4.
} 
generates the heard, whose fictionality is thus not parallel but equivalent: it is the sonic thing that I hear. In this way, sound produces a possible actual fiction rather than a possible parallel fiction and sounds as "world-creating predicate" the generative environment of its own truth that articulates in excess of the semantic. ${ }^{22}$ While this position is achieved through an engagement with sonic materiality, sound also functions as concept and as sensibility and becomes a conduit, a portal into the appreciation of the invisible and the mobile dimension of the world, whatever material the art researcher is working with.

As concept and as sensibility of the ephemeral, sound triggers and informs a fiction that articulates the real unknown, the unthinkable, and the incomplete, without marginalising it in a parallel textual universe, by instead comprehending the actuality of invisible possibilities and offering a portal to access them. We share this portal tentatively in a writing that does not obey the rationale of analytical language, its prejudices and expectations, but engages the capacity of sound to write the unheard. This is a language that sounds the laughter of feminine writing, as described by Cixous in her 1976 text The Laugh of the Medusa. It is a seemingly "impregnable" language "that will wreck partitions, classes, and rhetorics, regulations and codes" and becomes accessible only "in the act" of reading as an involved inhabiting ${ }^{23}$ : moving, doing, reading; to make it bare its consequences on the disciplinary framework it is challenging by necessity of its opaque inarticulacy.

Sonic fictions do not propose a bridge between the actual and the possible but make the possibility of actuality apparent, building reality in the contingent and rickety shape of its formless form. Thus, art research as sonic fiction is a generative fiction, rather than a referential fiction. It is designed from the actions of its materiality, not as description or reference of an object as source, but as the invisible shape of the process itself. We inhabit this ephemeral materiality intersubjectively, reciprocating its agency in the sensory-motor action of a 'listening reading' as a movement toward the text. In this way, we gain access to the invisible process of the work and come to an articulation that is not invested in nouns but in the predicate, in the doing and the mobility of research.

\section{Conclusion}

Maybe rather than agonising over a legitimate and reproducible and thus reliable language for art research, where comparisons can take place, consensus 
achieved and the outcome repeated, we have to acknowledge that art's knowledge is practical, contingent and fleeting, potentially unrepeatable. The performance of its expression, therefore, constitutes an overflow and a nondesignation that confronts us not only with the possibility of artistic sense but also with the limits of analytic language and academic knowledge. Thus while I write in favour of an engagement with art as research that borrows from the literary and the possibility of fiction - not to destroy artistic and aesthetic knowledge, its ambiguity, incompleteness, and, at times, sheer absence, but to foster the unreliable and unfinishable aspects of its production through literature's capacity to be ambiguous and incomplete-I am weary of a disciplinary takeover. Literature cannot speak for art. It can lend it tools and become a modest collaborator maybe, but as soon as it speaks in its stead it obstructs the knowledge pathway art burrows for itself in the unthinkable processes of its production, and that it presents unseen on the surface of its sensorial self. Only from the invisible and unexpected aspects of artistic production and with a sonic sensibility, a language can be derived that takes account of arts' own invisible sense.

There is a politics and an ethics in the refusal of art research to fill the taxonomic frame of a Kantian consciousness, whose knowledge enables but also demands and necessitates a categorical understanding of the world that relies on rather than critiques the prejudices of its base. The lexical definitions of gender, race, class, form, materiality, etc. describe normative identities whose certainty cannot be challenged with the language that categorises them so. Therefore while such categorical understanding legitimises and strengthens the notion of abstract knowledge, granting it authority, the socioeconomic asymmetries of its language reveal its construction and the ideologies of its build. By contrast, the unspeakable of art and the plurality of its processes, when speaking in its mother tongue, can question the ideologies of referential definitions and can challenge its exclusions, generating actual possible fictions and as yet impossible authorships.

Because it is not only about what knowledge but also whose knowledge. The heterogeneity of authorship is a central concern of artistic research, circumventing the base of normative sense through the radical nature of a speechless production. Thus, rather than fitting the volatile sense of art into the academic frame, scholarship has to question more rigorously the implication of its subjectivity and authority, and the limitation of its language on what it can find out about the world.

The political possibility of art research lies in its speechlessness as a refusal of normative sense and its ideological investments. It should not be coerced into the shape of a pre-existing language, literary or otherwise. Instead, it 
should be given the space and time to critique the conventions of language that determine and confirm the reliable, the consensual and the apparently true, and to activate alternatives that are not ventriloquised or marginalised but 'throw' their own voice.

Thus maybe rather than staring in the headlights and accepting being spoken for, artists as researchers need to sit down with their own tools, their mother tongue, and a dummy of their own to scream and shout, whisper and (in-) articulate the possibility of the incomplete, and enact the possibility of the impossible. Since art research when speaking in its own voice ruptures the rationale of taxonomical language and transforms its definitions. It can do so for example through a technologically aided ventriloquy that does not speak another's words, but pluralises and extends its articulation to amplify its sphere of influence, just like Andrea Pensado live at the Back Alley Theater: https://www .youtube.com/watch?v=KspVGrJrhpg.

\section{Bibliography}

Borgdorff, Henk, "The Production of Knowledge in Artistic Research," in: Michael Biggs/Henrik Karlsson, eds., The Routledge Companion to Research in the Arts. London: Routledge, 2012, pp. 44-63.

Caygill, Howard, A Kant Dictionary. Oxford: Blackwells, 1996.

Cixous, Hélène, "The Laugh of the Medusa" (1975), translated by Keith Cohen and Paula Cohen, in: Elaine Marks/Isabelle de Courtivron, eds., New French Feminisms. Hemel Hempstead: Harvester Wheatsheaf, 1981, pp. 245-264.

Cixous, Hélène/Catherine Clément, The Newly Born Woman (1975), translated by Betsy Wing. London: I.B. Tauris Publishers, 1996.

Eshun, Kodwo, More Brilliant than the Sun: Adventures in Sonic Fiction. London: Quartet Books, 1998.

Kristeva, Julia, Revolution in Poetic Language (1974), translated by Margaret Waller. New York, NY: Columbia University Press, 1984.

Manning, Erin/Brian Massumi, Thought in the Act:Passages in the Ecology of Experience. Minneapolis, MN: University of Minnesota Press, 2014.

Ronen, Ruth, Possible Worlds in Literary Theory. Cambridge: Cambridge University Press, 1994.

Ryan, Marie-Laure, Possible Worlds, Artificial Intelligence, and Narrative Theory. Bloomington, IN: Indiana University Press, 1991.

Worden, Jessica, "Articulating Breath: Writing Charcot's Hysteric with Performance Writing," in: New Voices Forum, Arts \& Humanities in Higher Education 3:3 (2014), pp. $318-325$. 